\title{
Evaluasi Pelaksanaan Standar Pelayanan Farmasi Di Rumah Sakit Umum Daerah Kelas C di Propinsi Nusa Tenggara Barat
}

\author{
M. Sidrotullah 1*, Khairil Pahmi ${ }^{2}$ \\ 1,2 Program Studi Farmasi DIII, Fakultas Ilmu Kesehatan, Universitas Nahdlatul Wathan Mataram, \\ Jl. Merdeka Raya, Karang Pule, Mataram
}

* Penulis Korespondensi. Email: sidrotullah85@gmail.com

ABSTRAK

Instalasi Farmasi sebagai tempat pengabdian profesi di rumah sakit dan salah satu unit pelayanan utama rumah sakit mempunyai peran dan fungsi yang sangat penting dalam menunjang pelayanan kesehatan yang bermutu. Salah satu usaha untuk meningkatkan mutu pelayanan instalasi farmasi dapat dilakukan dengan melaksanakan standar pelayanan farmasi rumah sakit. Penelitian ini bertujuan untuk mengetahui gambaran Pelaksanaan Standar Pelayanan Kefarmasian di Rumah Sakit Umum Daerah Kelas C di Propinsi Nusa Tenggara Barat, serta faktor pendukung atau penghambat dalam pelaksanaan.

Penelitian ini merupakan penelitian deskriptif. Penelitian dilakukan di 3 Rumah Sakit Umum Daerah Kelas C di Propinsi Nusa Tenggara Barat. Pengumpulan data dilakukan menggunakan pedoman wawancara pelaksanaan standar pelayanan farmasi rumah sakit. Penilaian meliputi tujuh standar yang terbagi dalam dua puluh tiga parameter. Suatu Instalasi Farmasi Rumah Sakit dikatakan telah sesuai dengan standar jika nilai persentase rata-rata pencapaian standar lebih dari $75 \%$ sebaliknya jika kurang dari 75\% dikatakan tidak sesuai standar.

Hasil penelitian menunjukkan bahwa pelaksanaan standar pelayanan kefarmasian di Rumah Sakit Umum Daerah Kelas C di Propinsi Nusa Tenggara Barat belum terlaksana dengan baik, ini dapat dilihat dari hasil yang menunjukkan persentase pencapain standar dari ketiga rumah sakit masih kurang dari 75 \%. Persentase pencapain standar dari Rumah Sakit A (52,17\%), Rumah Sakit B (54,78\%) dan Rumah Sakit C (44,35\%).

Kata Kunci:

Evaluasi, Standar Pelayanan Farmasi, RSUD

$\begin{array}{lcc}\text { Diterima: } & \text { Disetujui: } & \text { Online: } \\ \text { 20-09-2019 } & 1-12-2019 & 18-02-2020\end{array}$

\section{ABSTRACT}

Pharmacy as a place for a main and professional service in hospital has the important role for supporting quality health services. One attempt to improve the quality of pharmaceutical care was by implementing the standards of hospital pharmaceutical care. The research aimed at finding out illustration of the implementation of pharmaceutical care standard at Local Public Hospitals Class C in Nusa Tenggara Barat province, as well as supporting or obstacle factors in the implementation.

This research was a descriptive study. The study was conducted in three local public hospitals class $C$ in Nusa Tenggara Barat province. Data was collected by using interview method of pharmacy hospital service standard. This interview comprises seven standards that are divided in twenty three parameters. The Pharmacy Department is agree with standard if the percentage of mean score was more than $75 \%$, the other way it is not agree with standard if the percentage of mean score was less than $75 \%$.

The research result showed that the implementation of pharmaceutical care standard at Local Public Hospitals Class C in Nusa Tenggara Barat province had not implemented well yet, 
which could be seen from the result showing the percentage of standard achievement of three hospitals were less than $75 \%$. The percentage of standard achievement of hospital A was 52, $12 \%$, hospital B was $54,78 \%$, and hospital C was $44,35 \%$.

Keywords:

Evaluation, Standard of Pharmaceutical Care, The Local Public

$\begin{array}{ccc}\text { Received: } & \text { Accepted: } & \text { Online: } \\ \text { 2019-09-20 } & 2019-12-1 & 2020-02-18\end{array}$

\section{Pendahuluan}

Rumah sakit adalah salah satu sarana kesehatan tempat menyelenggarakan upaya kesehatan. Menurut Undang-Undang Kesehatan No. 36 tahun 2009 yang dimaksud upaya kesehatan adalah setiap kegiatan dan/atau serangkaian kegiatan yang dilakukan secara terpadu, terintregasi dan berkesinambungan untuk memelihara dan meningkatkan derajat kesehatan masyarakat dalam bentuk pencegahan penyakit, peningkatan kesehatan, pengobatan penyakit, dan pemulihan kesehatan oleh pemerintah dan/atau masyarakat [1]. Secara lebih ringkas, fungsi rumah sakit mempunyai empat fungsi dasar, yaitu pelayanan penderita, pendidikan, pelatihan, dan kesehatan masyarakat [15]

Instalasi farmasi sebagai salah satu tempat pelayanan rumah sakit adalah bagian yang tidak terpisahkan dari sistem pelayanan kesehatan rumah sakit yang berorientasi kepada pelayanan pasien, penyediaan obat yang bermutu, termasuk pelayanan farmasi klinik yang terjangkau bagi semua lapisan masyarakat [3]. Pelayanan Instalasi Farmasi Rumah Sakit yang bermutu haruslah menjadi perhatian pimpinan rumah sakit, karena Insatalasi Farmasi Rumah Sakit merupakan unit yang mempunyai pengaruh besar dan sangat strategis di suatu rumah sakit, dapat dilihat bahwa besarnya kontribusi sektor farmasi di rumah sakit dapat mencapai 50\% hingga 60\% dari anggaran rumah sakit [16]. Selain itu pelayanan farmasi yang mengacu pada Pharmaceutical Care bisa dijelaskan sebagai suatu proses kerjasama farmasis dengan pasien dan profesi lain dalam mendesain, mengimplementasi, dan memonitor rencana terapi yang akan menghasilkan outcome terapi khusus bagi pasien [9].

Sebagai upaya agar IFRS dapat melaksanakan pelayanan kefarmasian yang profesional dan menjamin mutu pelayanan kefarmasian kepada masyarakat, telah dikeluarkan keputusan menteri kesehatan nomor 1197 /Menkes /SK /X /2004 tentang Standar Pelayanan Farmasi di Rumah Sakit. Dalam standar tersebut disebutkan bahwa saat ini tuntutan pasien dan masyarakat akan mutu pelayanan farmasi, mengharuskan adanya perubahan pelayanan dari paradigma lama (drug oriented) ke paradigma baru (patient oriented) dengan filosofi Pharmaceutical Care (pelayanan kefarmasian) [2]. Sehingga harapan terhadap tercapainya kepuasan pasien pada pelayanan Instalasi Farmasi Rumah Sakit belum dapat diwujudkan. Dengan aadanya pengesahan standar pelayanan farmasi tersebut menjadi wajib bagi semua rumah sakit untuk menerapkannya tanpa memandang kelas dan status kepemilikannya, serta menjadi acuan bagi farmasis yang bekerja di rumah sakit untuk melaksanakan aktifitas profesinya dalam upaya meningkatkan mutu pelayanan [4].

Berdasarkan hal tersebut diatas, maka perlu dilakukan penelitian tentang pelaksanaan standar pelayanan farmasi seperti yang tertuang dalam keputusan menteri kesehatan nomor 1197 / Menkes /SK / X / 2004 di rumah sakit umum daerah pemerintah kelas C di Propinsi Nusa Tenggara Barat, agar dapat diketahui pelaksanaan standar pelayanan farmasi di rumah sakit dan faktor-faktor pendukung ataupun faktor penghambat dalam 
pelaksanaan standar tersebut, sebagai langkah strategis untuk menentukan keputusan manajerial pihak rumah sakit dalam meningkatkan mutu pelayanan kepada pasien.

\section{Metode Penelitian}

2.1 Subyek Penelitian

Subjek Penelitian adalah Instalasi Farmasi Rumah Sakit Pemerintah Kelas C di Propinsi Nusa Tenggara Barat, yaitu : RSU Patut Patuh Patju, RSU Praya, dan RSU Soedjono Selong.

2.2. Alat Penelitian

Alat penelitian yang digunakan dalam penelitian ini adalah Pedoman Wawancara Pelaksanaan Standar Pelayanan Farmasi Rumah Sakit, tape recorder serta buku dan alat tulis.

2.3 Jalannya Penelitian

Tahap persiapan

Pada tahap ini dilakukan pembuatan proposal dan perizinan yang ditujukan ke pimpinan / direktur rumah sakit.

Tahap pelaksanaan

Pada tahap ini dilakukan penilaian terhadap pelaksanaan standar pelayanan di Instalasi Farmasi di Rumah Sakit Umum Daerah Kelas C di Propinsi Nusa Tenggara Barat. Penilaian dilaksanakankan dengan melakukan wawancara menggunakan pedoman wawancara dan dengan melihat bukti-bukti pendukung, serta melakukan wawancara akhir dengan Kepala Instalasi Farmasi Rumah Sakit untuk mendapatkan faktor-faktor pendukung atau penghambat pelaksanaan standar pelayanan farmasi rumah sakit.

Tahap pengolahan data

Pada tahap ini data yang diperoleh dilakukan analisis untuk mengetahui sejauh mana Pelaksanaan Standar Pelayanan Farmasi di Rumah Sakit Umum Daerah Kelas C di Propinsi Nusa Tenggara Barat melalui perhitungan skor dan persentase. Untuk selanjutnya dilakukan evaluasi faktor pendukung dan penghambat terhadap pencapaian standar tersebut.

Analisis Data

Data yang didapat dari hasil perolehan skor pada Pedoman Wawancara Pelaksanaan Standar Pelayanan Farmasi Rumah Sakit dinilai dengan mengacu pada penilaian akreditasi rumah sakit, yaitu (Aulia, 2006) :

\section{Persentase Pencapaian} Standar $=$

$$
\frac{\text { Jumlah nilai }}{\text { Jumlah parameter yang dinilai x } 5} \times 100 \%
$$

Suatu instalasi farmasi dikatakan telah memenuhi standar jika nilai persentase rata-rata pencapaian standar lebih dari 75\%, sebaliknya jika kurang dari 75\% dikatakan tidak memenuhi standar (Aulia, 2006). Untuk memperoleh gambaran pelaksanaan setiap standar, digunakan uji nilai rata-rata (uji mean) pencapaian skor dalam persen (\%), nilai perolehan rata-rata kemudian dibandingkan dengan persentase standar (75\%).

3. Hasil dan Pembahasan

Karakteristik Rumah Sakit tempat melakukan penelitian. Rumah sakit tempat dilakukannya penelitian adalah Rumah Sakit Umum Pemerintah Kelas C yang ada di Provinsi Nusa Tenggara Barat. Rumah Sakit Umum Pemerintah Kelas C menurut Undang-Undang Nomor 44 Tahun 2009 adalah rumah sakit umum yang mempunyai fasilitas dan kemampuan pelayanan medik paling sedikit 4 (empat) spesialis dasar dan 4 (empat) spesialis penunjang medik [6]. Berikut dalam tabel I disajikan profil rumah sakit yang menjadi subyek penelitian ini. 
Tabel I. Profil Rumah Sakit

\begin{tabular}{cccc}
\hline & Rumah Sakit A & Rumah Sakit B & Rumah Sakit C \\
\hline Jumlah Tempat Tidur & 110 & 147 & 222 \\
Bed Occupation Rate (\%) & 66,02 & 84,08 & 78 \\
Length of Stay (hari) & 4 & 3 & 4 \\
Apoteker & 3 & 4 & 5 \\
Asisten Apoteker & 5 & 6 & 3 \\
Administrasi & 2 & 6 & 6 \\
Resep Rawat Inap & 63 & 120 & 120 \\
Resep Rawat Jalan & 75 & 74 & 90 \\
Total Resep Perhari & 138 & 194 & 210 \\
\hline
\end{tabular}

Perolehan Skor Setiap Standar

Standar satu adalah standar yang mengatur tentang adanya falsafah dan tujuan tertulis instalasi Farmasi Rumah Sakit yang mencerminkan peran atau fungsi pelayanan farmasi di rumah sakit. Dalam standar ini hanya ada satu parameter penilaian, yaitu ada atau tidaknya falsafah dan tujuan tertulis Instalasi Farmasi Rumah Sakit. Perolehan skor pada standar satu di tempat rumah sakit terlihat pada Tabel II berikut ini:

Tabel II. Perolehan Skor Tiga Rumah Sakit Pada Standar Satu Tentang Falsafah dan Tujuan

\begin{tabular}{cccccc}
\hline Rumah Sakit & Parameter & Skor & $\begin{array}{c}\text { Persentase } \\
\text { skor } \mathbf{( \% )}\end{array}$ & $\begin{array}{c}\text { Rata-Rata } \\
\text { Persentase } \\
\text { skor }(\mathbf{\%})\end{array}$ & Keterangan \\
\hline A & 1 & 0 & 0,00 & 0 & Tidak Sesuai \\
B & 2 & 4 & 80,00 & 80,00 & Sesuai \\
C & 3 & 0 & 0,00 & 0 & Tidak Sesuai \\
\hline
\end{tabular}

Tabel II menunjukkan bahwa pada standar satu, didapat hanya satu rumah sakit yang sudah melebihi pencapaian standar $75 \%$, yaitu rumah sakit B dengan perolehan skor $80 \%$.

Standar dua adalah standar yang mengatur tentang administrasi dan pengelolaan Instalasi Farmasi Rumah Sakit. Dalam standar ini ada tiga parameter penilaian, yaitu adanya bagan organisasi yang menggambarkan pembagian tugas, koordinasi, dan kewenangan; adanya keterlibatan apoteker dalam Panitia Farmasi dan Terapi (PFT); serta keterlibatan apoteker dalam Panitia Pengendalian Infeksi Rumah Sakit (PPIRS) atau Panitia Infeksi Nosokomial (PIN). Perolehan skor pada standar dua di tiga rumah sakit dapat dilihat pada tabel III berikut ini:

Tabel III. Perolehan Skor Tiga Rumah Sakit Pada Standar Dua Tentang Administrasi dan Pengelolaan.

\begin{tabular}{cccccc}
\hline $\begin{array}{c}\text { Rumah } \\
\text { Sakit }\end{array}$ & Parameter & Skor & $\begin{array}{c}\text { Persentase } \\
\text { skor (\%) }\end{array}$ & $\begin{array}{c}\text { Rata-rata } \\
\text { Persentase } \\
\text { skor (\%) }\end{array}$ & Keterangan \\
\hline A & 1 & 4 & 80,00 & 53,33 & Tidak Sesuai \\
& 2 & 3 & 60,00 & & \\
& 3 & 1 & 20,00 & & Tidak Sesuai \\
B & 1 & 4 & 80,00 & 53,33 & \\
& 2 & 3 & 60,00 & &
\end{tabular}




$\begin{array}{cccccc} & 3 & 1 & 20,00 & & \\ \text { C } & 1 & 4 & 80,00 & 46,67 & \text { Tidak Sesuai } \\ & 2 & 3 & 60,00 & & \\ & 3 & 0 & 0,00 & & \\ & & & \end{array}$

Pada tabel III menunjukkan bahwa pada standar dua, persentase pencapaian standar ketiga rumah sakit masih kurang dari $75 \%$, yaitu dengan perolehan skor masingmasing, rumah sakit A 53,33\%, rumah sakit B 53,33\% dan rumah sakit C 46,67\%.

Standar tiga adalah standar yang mengatur tentang staff dan pimpinan. Dalam standar ini ada tiga parameter penilaian, yaitu syarat administrasi dan hukum Kepala Instalasi Farmsi, jumlah tenaga kefarmasian, serta adanya evaluasi penilaian kinerja karyawan yang dilakukan berdasarkan tugas yang terkait dengan pekarjaan fungsional yang diberikan. Perolehan skor pada standar tiga di tiga rumah sakit terdapat dalam tabel IV berikut ini:

Tabel IV. Perolehan Skor Tiga Rumah Sakit Pada Standar Tiga Tentang Staf dan Pimpinan.

\begin{tabular}{cccccc}
\hline $\begin{array}{c}\text { Rumah } \\
\text { Sakit }\end{array}$ & Parameter & Skor & $\begin{array}{c}\text { Persentase } \\
\text { skor (\%) }\end{array}$ & $\begin{array}{c}\text { Rata-Rata } \\
\text { Persentase } \\
\text { skor (\%) }\end{array}$ & Keterangan \\
\hline A & 1 & 5 & 100,00 & 86,67 & Sesuai \\
& 2 & 3 & 60,00 & & \\
B & 3 & 5 & 100,00 & & Sesuai \\
& 1 & 5 & 100,00 & 86,67 & \\
& 2 & 3 & 60,00 & & Sesuai \\
C & 3 & 5 & 100,00 & & \\
& 1 & 5 & 100,00 & 86,67 & \\
& 2 & 3 & 60,00 & & \\
\hline
\end{tabular}

Pada tabel IV menunjukkan bahwa pada standar tiga, seluruh rumah sakit sudah melebihi pencapaian standar $75 \%$, yaitu ketiga rumah sakit mendapat perolehan skor $86,67 \%$. Ini berarti ketiga rumah sakit telah sesuai dengan standar.

Standar empat adalah standar yang mengatur tentang fasilitas dan peralatan yang menunjang pelaksanaan pelayanan farmasi. Dalam standar ini ada lima parameter penilaian, yaitu ada tidaknya ruangan untuk kegiatan produksi/ pengemasan kembali, ruang penyimpanan perbekalan farmasi, ruang distribusi, ruang konsultasi/konseling, serta ruang pelayanan informasi obat. Perolehan skor pada standar empat di tiga rumah sakit terdapat dalam Tabel V berikut ini:

Tabel V. Perolehan Skor Tiga Rumah Sakit Pada Standar Empat Tentang Fasilitas dan Peralatan.

\begin{tabular}{cccccc}
\hline $\begin{array}{c}\text { Rumah } \\
\text { Sakit }\end{array}$ & Parameter & Skor & $\begin{array}{c}\text { Persentase } \\
\text { skor (\%) }\end{array}$ & $\begin{array}{c}\text { Rata-Rata } \\
\text { Persentase } \\
\text { skor (\%) }\end{array}$ & Keterangan \\
\hline A & 1 & 0 & 0,00 & 28,00 & Tidak Sesuai \\
& 2 & 4 & 80,00 & & \\
& 3 & 1 & 20,00 & & \\
& 4 & 1 & 20,00 & & \\
\hline
\end{tabular}




\begin{tabular}{cccccc}
\hline \multirow{3}{*}{ B } & 5 & 1 & 20,00 & & \\
& 1 & 0 & 0,00 & 28,00 & Tidak Sesuai \\
& 2 & 4 & 80,00 & & \\
& 3 & 1 & 20,00 & & \\
& 4 & 1 & 20,00 & & \\
& 5 & 1 & 20,00 & & \\
& 1 & 0 & 0,00 & 28,00 & Tidak Sesuai \\
& 2 & 4 & 80,00 & & \\
& 3 & 1 & 20,00 & & \\
& 4 & 1 & 20,00 & & \\
\hline
\end{tabular}

Pada tabel V menunjukkan bahwa pada standar empat, persentase pencapaaian standar ketiga rumah sakit masih kurang dari $75 \%$, yaitu dengan perolehan skor masingmasing, rumah sakit A 28,00\%; rumah sakit B 28,00\% dan rumah sakit C 28,00\%.

Standar lima adalah standar yang mengatur tentang kebijakan dan prosedur pelayanan farmasi, serta tentang pelaksanaan kegiatan pelayanan kefarmasian. Dalam standar ini ada enam parameter penilaian, yaitu kelengkapan kebijakan pelayanan farmasi, kegiatan pengelolaan perbekalan farmasi, kegiatan pengkajian resep, kegiatan konseling, kegiatan pelayanan informasi obat, serta kegiatan visite pasien. Perolehan skor pada standar lima di tiga rumah sakit terdapat dalam tabel VI berikut ini:

Tabel VI. Perolehan Skor Tiga Rumah Sakit Pada Standar Lima Tentang Kebijakan dan Prosedur

\begin{tabular}{|c|c|c|c|c|c|}
\hline Rumah Sakit & Parameter & Skor & $\begin{array}{c}\text { Persentase } \\
\text { skor }(\%)\end{array}$ & $\begin{array}{c}\text { Rata-Rata } \\
\text { Persentase } \\
(\%)\end{array}$ & Keterangan \\
\hline \multirow[t]{6}{*}{ A } & 1 & 3 & 60,00 & 60,00 & Tidak Sesuai \\
\hline & 2 & 5 & 100,00 & & \\
\hline & 3 & 4 & 80,00 & & \\
\hline & 4 & 4 & 80,00 & & \\
\hline & 5 & 2 & 40,00 & & \\
\hline & 6 & 0 & 0,00 & & \\
\hline \multirow[t]{6}{*}{ B } & 1 & 3 & 60,00 & 56,67 & Tidak Sesuai \\
\hline & 2 & 5 & 100,00 & & \\
\hline & 3 & 4 & 80,00 & & \\
\hline & 4 & 3 & 60,00 & & \\
\hline & 5 & 2 & 40,00 & & \\
\hline & 6 & 0 & 0,00 & & \\
\hline \multirow[t]{6}{*}{$\mathrm{C}$} & 1 & 3 & 60,00 & 50,00 & Tidak Sesuai \\
\hline & 2 & 5 & 100,00 & & \\
\hline & 3 & 4 & 80,00 & & \\
\hline & 4 & 1 & 20,00 & & \\
\hline & 5 & 2 & 40,00 & & \\
\hline & 6 & 0 & 0,00 & & \\
\hline
\end{tabular}


Pada tabel VI menunjukkan bahwa pada standar lima, persentase pencapaaian standar ketiga rumah sakit masih kurang dari $75 \%$, yaitu dengan perolehan skor masingmasing, rumah sakit A $60 \%$, rumah sakit B 56,67\% dan rumah sakit C $50 \%$.

Standar enam adalah standar yang mengatur tentang pengembangan staff dan program pendidikan. Dalam standar ini ada dua parameter penilaian, yaitu adanya program orientasi/pelatihan bagi pegawai baru di IFRS, serta adanya program pendidikan maupun pelatihan bagi semua petugas farmasi untuk meningkatkan keterampilan, pengetahuan, dan kemampuan. Perolehan skor pada standar enam di tiga rumah sakit terdapat dalam Tabel VII berikut ini:

\begin{tabular}{cccccc}
\multicolumn{6}{c}{ Tabel VII. Perolehan Skor Tiga Rumah Sakit Pada Standar Enam Tentang } \\
Pengembangan Staf dan Program Pendidikan & \\
\hline $\begin{array}{c}\text { Rumah } \\
\text { Sakit }\end{array}$ & Parameter & Skor & $\begin{array}{c}\text { Persentase } \\
\text { skor (\%) }\end{array}$ & $\begin{array}{c}\text { Rata-Rata } \\
\text { Persentase } \\
\text { skor (\%) }\end{array}$ & Keterangan \\
& & & & & Sesuai \\
A & 1 & 4 & 80,00 & 80,00 & Sesuai \\
& 2 & 4 & 80,00 & & \\
B & 1 & 4 & 80,00 & 80,00 & \\
& 2 & 4 & 80,00 & & Tidak Sesuai \\
C & 1 & 4 & 80,00 & 50,00 & \\
& 2 & 1 & 20,00 & & \\
\hline
\end{tabular}

Pada tabel VII menunjukkan bahwa pada standar enam, ada dua rumah sakit yang sudah melebihi pencapaian standar 75\%, satu rumah sakit lainnya masih di bawah pencapaian standar $75 \%$, yaitu dengan perolehan skor masing-masing, rumah sakit $\mathrm{A}$ $80 \%$, rumah sakit B $80 \%$ dan rumah sakit C 50\%.

Standar tujuh adalah standar yang mengatur tentang evaluasi dan pengendalian mutu. Dalam standar ini ada tiga parameter penilaian, yaitu adanya program peningkatan mutu pelayanan farmasi, kelengkapan data mengenai pelayanan farmasi, serta adanya kegiatan pertemuan rutin instalasi farmasi. Perolehan skor pada standar tujuh di tiga rumah sakit terdapat dalam Tabel VIII berikut ini:

Tabel VIII. Perolehan Skor Tiga Rumah Sakit Pada Standar Tujuh Tentang Tentang Evaluasi dan Pengendalian Mutu

\begin{tabular}{cccccc}
\hline Rumah Sakit & Parameter & Skor & $\begin{array}{c}\text { Persentase } \\
\text { skor (\%) }\end{array}$ & $\begin{array}{c}\text { Rata-Rata } \\
\text { Persentase } \\
\text { skor (\%) }\end{array}$ & Keterangan \\
\hline A & 1 & 0 & 0,00 & 40,00 & Tidak Sesuai \\
& 2 & 2 & 40,00 & & \\
B & 3 & 4 & 80,00 & & Tidak Sesuai \\
& 1 & 0 & 0,00 & 40,00 & \\
& 2 & 2 & 40,00 & & Tidak Sesuai \\
C & 3 & 4 & 80,00 & & \\
& 1 & 0 & 0,00 & 26,67 & \\
& 2 & 2 & 40,00 & & \\
\hline
\end{tabular}

Pada tabel VIII menunjukkan bahwa pada standar tujuh, persentase pencapaaian standar ketiga rumah sakit masih kurang dari 75\%, yaitu dengan perolehan skor 
masing-masing rumah sakit A 40\%, rumah sakit B 40\% dan rumah sakit C 26,67\%. Dengan kata lain pelaksanaan standar tujuh mengenai evaluasi dan pengendalian mutu Berdasarkan perolehan skor setiap standar tersebut, dapat dibuat perolehan skor ratarata pelaksanaan masing-masing standar pelayanan farmasi di Rumah Sakit Pemerintah Kelas C di Provinsi Nusa Tenggara Barat, seperti terlihat pada tabel IX berikut ini :

Tabel IX. Perolehan Skor Rata-Rata Pelaksanaan Standar Pelayanan Farmasi di Rumah Sakit Pemerintah Kelas C di Provinsi NTB

\begin{tabular}{cccccccc}
\hline Rumah & \multicolumn{7}{c}{ Perolehan Skor Rata-Rata Setiap Standar } \\
\cline { 2 - 8 } Sakit & 1 & 2 & 3 & 4 & 5 & 6 & 7 \\
\hline A & $0 \%$ & $53,33 \%$ & $86,67 \%$ & $28 \%$ & $60 \%$ & $80 \%$ & $40 \%$ \\
B & $80 \%$ & $53,33 \%$ & $86,67 \%$ & $28 \%$ & $56,67 \%$ & $80 \%$ & $40 \%$ \\
C & $0 \%$ & $46,67 \%$ & $86,67 \%$ & $28 \%$ & $50 \%$ & $50 \%$ & $26,67 \%$ \\
\hline
\end{tabular}

Dari tabel IX diatas terlihat bahwa, persentase pencapaian standar paling tinggi diperoleh oleh standar tiga yaitu tentang staff dan pimpinan dimana ke tiga rumah sakit telah memenuhi standar dengan perolehan skor yang sama yaitu $86,67 \%$.

Perolehan Skor Total Pelaksanaan Standar Pelayanan Farmasi

Perolehan skor total standar pelayanan farmasi di tiga rumah sakit diperoleh dengan menjumlahkan skor setiap parameter masing-masing rumah sakit, kemudian dihitung persentase skor setiap rumah sakit untuk menentukan apakah rumah sakit telah sesuai standar. Suatu instalasi farmasi dikatakan telah memenuhi standar jika nilai persentase pencapaian standar lebih dari 75\%, sebaliknya jika kurang dari 75\% dikatakan belum memenuhi standar [12]. Perolehan skor total ini dapat dilihat lebih jelas pada tabel X berikut :

\begin{tabular}{l} 
Tabel X. Perolehan Skor Total Pelaksanaan Standar Pelayanan Farmasi di Tiga \\
Rumah Sakit Pemerintah Kelas C di Propinsi \\
\cline { 2 - 4 } \\
\begin{tabular}{ccccc} 
Rumah Sakit & A & B & Tenggara Barat \\
\cline { 2 - 4 } Skor total & 60 & 63 & C \\
\% Skor & 52,17 & 54,78 & 44,35 \\
Keterangan & Tidak sesuai Tidak sesuai & Tidak sesuai \\
\hline
\end{tabular}
\end{tabular}

Berdasarkan Tabel $\mathrm{X}$ diatas, diketahui bahwa perolehan persentase skor total pelaksanaan standar pelayanan farmasi di rumah sakit pemerintah kelas $C$ di propinsi Nusa Tenggara Barat masih belum memenuhi standar pelayanan farmasi rumah sakit, karena perolehan skor total masing-masing rumah sakit masih kurang dari 75\%, dan jika dibandingkan dengan penelitian sebelumnya yang pernah dilakukan oleh Aulia (2006) Pada rumah sakit B yang menjadi faktor penghambat pelaksanaan standar pelayanan farmasi di rumah sakit adalah belum optimalnya dukungan dari jajaran direksi dan manajemen rumah sakit [8]. Faktor lain yang juga menjadi penghambat adalah jumlah ketenagaan yang masih kurang, serta dokumentasi yang kurang baik, dimana beberapa kegiatan yang dilaksanakan masih belum terdokumentasi, padahal dokumentasi kegiatan sangat penting dilakukan sebagai data nyata untuk melakukan evaluasi lebih lanjut dan perbaikan kinerja pelayanan farmasi. Dalam hal ini, perlu adanya evaluasi yang terus menerus baik dari pihak manajemen rumah sakit ataupun instalasi farmasi terhadap pelayanan farmasi yang dilakukan, agar kekurangan dan permasalahanpermasalahan yang terjadi di Instalasi Farmasi Rumah Sakit dapat terselesaikan dengan baik. 
Sedang yang menjadi faktor penghambat pelaksanaan standar pelayanan farmasi rumah sakit di Rumah Sakit C yaitu terutama lemahnya dukungan dan evaluasi manajemen rumah sakit. Seharusnya, pihak manajemen Rumah Sakit C melakukan suatu perencanaan, pengendalian, dan perbaikan sistem kualitas, sehingga dalam hal ini Instalasi Farmasi dapat melaksanakan standar pelayanan dengan baik. Ini dapat saja tercapai apabila komitmen, keterlibatan, dan dukungan dari pihak manajemen rumah sakit terus dioptimalkan, kemudian Kepala Instalasi Farmasi juga harus lebih proaktif dalam menyikapi permasalahan-permasalahan yang ada di instalasi farmasi, serta melakukan kerja sama yang baik dengan melibatkan seluruh staf yang ada untuk mendukung komitmen perbaikan tersebut. Faktor lain yang juga menjadi penghambat adalah Rumah Sakit C belum melaksanakan sistem pelayanan farmasi satu pintu, ini dapat dilihat dari masih adanya apotek lain didalam lingkungan rumah sakit selain IFRS itu sendiri. Hal tersebut mengakibatkan keterjaringan dan kepuasan pasien menjadi berkurang, akibat resep dokter yg diterima pasien juga dapat dilayani oleh apotek lain selain IFRS, sehingga dari segi pendapatan dan kesejahteraan rumah sakit menjadi kurang maksimal. Upaya kedepan, perlu adanya suatu kebijakan mengenai sistem pelayanan farmasi satu pintu di rumah sakit $C$, sehingga pengelolaan obat dan barang farmasi hanya dilakukan oleh instalasi farmasi sebagai satu-satunya unit bisnis yang mengelola peredaran dan penggunaan obat di rumah sakit, sesuai dengan yang tertuang dalam UU No.44 Tahun 2009 pada pasal 15 ayat 3 yang menyatakan bahwa pengelolaan alat kesehatan, sediaan farmasi, dan bahan habis pakai di Rumah Sakit harus dilakukan oleh Instalasi Farmasi menggunakan sistem satu pintu [10].

\section{Kesimpulan}

Hasil penelitian menunjukkan bahwa pelaksanaan standar pelayanan kefarmasian di Rumah Sakit Pemerintah Kelas C di Provinsi Nusa Tenggara Barat belum terlaksana dengan baik, ini dapat dilihat dari hasil yang menunjukkan persentase pencapain standar dari ketiga rumah sakit masih kurang dari $75 \%$. Persentase pencapain standar dari Rumah Sakit A (52,17\%), Rumah Sakit B (54,78\%) dan Rumah Sakit C (44,35\%). Berdasarkan hasil wawancara, diketahui bahwa faktor penghambat pelaksanaan standar pelayanan farmasi adalah belum optimalnya dukungan pihak manajemen rumah sakit terhadap pelayanan farmasi yang dilakukan, pengadaan sarana dan prasarana penunjang pelaksanaan pelayanan farmasi yang masih belum memadai, kurangnya jumlah dan belum optimalnya tenaga farmasi yang ada di Instalasi Farmasi, sistem dokumentasi Instalasi Farmasi yang kurang baik, serta kurangnya evaluasi yang terus menerus dalam upaya peningkatan kinerja Instalasi Farmasi dalam melaksanakan pelayanan farmasi.

\section{Referensi}

[1] Aditama, T.Y., 2007, Manajemen Administrasi Rumah Sakit, Cetakan Kedua, Penerbit UI Press, Jakarta.

[2] Anonim, 2004, Keputusan Menteri Kesehatan RI Nomor 1197 /Menkes /SK / X /2004 tentang Standar Pelayanan Farmasi di Rumah Sakit, Direktorat Jenderal Pelayanan Kefarmasian dan Alat Kesehatan, Departemen Kesehatan RI, Jakarta.

[3] Anonim, 2005, Kebijakan Obat Nasional, Departemen Kesehatan Republik Indonesia, Jakarta. 
[4] Anonim, 2006, Pedoman Konseling Pelayanan Kefarmasian di Sarana Kesehatan, Direktorat Bina Farmasi Komunitas dan Klinik Ditjen Bina Kefarmasian dan Alat Kesehatan Departemen Kesehatan RI, Jakarta.

[5] Anonim, 2009a, Undang-undang Republik Indonesia No. 36 tahun 2009 Tentang Kesehatan, Departemen Kesehatan Republik Indonesia, Jakarta.

[6] Anonim, 2009b, Undang-undang Republik Indonesia No. 44 tahun 2009 Tentang Rumah Sakit, Departemen Kesehatan Republik Indonesia, Jakarta.

[7] Arce,B,G., Sanchez,L,G., Perea,N,M., Mainar, A,S., Tamayo,M,B., Navarro,C,P., (2009), ESCP 37th European Symposium on Clinical Pharmacy, Pharmaceutical Care Models, and Therapeutic Innovations, Dubrovnik, Croatia, 21-24 October 2008 : PC-19 Pharmacist Interventions in the Pharmacotherapy Follow-up of in-Patient, 31:246-349. Available from:<http://www. springer.com> (Accessed 10 April 2012).

[8] Aulia, N., 2006, Evaluasi Pelaksanaan Standar Pelayanan Farmasi di Rumah Sakit Tipe C di Daerah Istimewa Yogyakarta, Tesis S-2, Program Magister Ilmu Farmasi, Minat Manajemen Farmasi, Fakultas Farmasi, Universitas Gadjah Mada, Yogyakarta.

[9] Erah, P.O., dan Nwazouke, J.C., 2002, Identification of Standards for Pharmaceutical Care in Benin City, Faculty of Pharmacy, University of Benin, Benin City, Nigeria, Trop J Pharm Res. 2002; 1 (2): 55-66, (http://www.tjpr.org/vol1\%20no2/erah12a.pdf, diakses tanggal 8 september 2010)

[10] Kardinah, E.I., 2008, Evaluasi Pelaksanaan Standar Pelayanan Farmasi di Empat 9Rumah Sakit Tipe B di Daerah Khusus Ibukota Jakarta, Tesis S-2, Program Magister Ilmu Farmasi, Minat Manajemen Farmasi, Universitas Gadjah Mada, Yogyakarta.

[11] Makadia, Ms. Hiral A., Bhatt, Ms. Ami Y., Parmar, Mr. Ramesh B., Paun, Ms., 2013, Self-nano Emulsifying Drug Delivery System (SNEDDS): Future Aspect, Asian J. Pharm. Res., 3 (1) : 21-27.

[12] Notoatmodjo, S., 2003, Prinsip-Prinsip Dasar Ilmu Kesehatan Masyarakat, Cetakan Kedua, Rineka Cipta, Jakarta.

[13] Piscitelli, S.C dan Rodvold, K.A. 2005. Drug Interaction in Infection Disease Second Edition. New Jersey: Humana Press

[14] Prest, M.2003. Penggunaan Obat Pada Lanjut Usia dalam Aslam., M., Tan, C.K., Prayitno. A., (Eds), Farmasi Klinis (Clinical Pharmacy) : Menuju Pengobatan Rasional dan Penghargaan Pilihan Pasien, 203-214. Jakarta: PT Elex Media Komputindo

[15] Siregar, C.J.P. dan Amalia, Lia, 2004, Farmasi Rumah Sakit Teori dan Penerapan, ECG Penerbit Buku Kedokteran, Jakarta.

[16] Trisnantoro, L., 2004, Memahami Penggunaan Ilmu Ekonomi dalam Manajemen Rumah Sakit, Gadjah Mada University Press, Yogyakarta. 